\title{
Editorial Special Issue
}

\author{
Jiří Jaromír Klemeš • Igor Bulatov
}

Published online: 20 October 2010

(C) Springer-Verlag 2010

There is growing understanding that the environmental challenges facing mankind cannot be solved only by means of technological or societal sciences. A complex approach is needed, an approach that combines the strengths of novel developments in clean technologies and political implementation of the societal demands for sustainable development and clean environment. Considerable efforts are being made both in technical and political fields to pursue this goal and it is important for the scientific community and decision makers to be aware of those efforts. With this aim in mind, the organisers of the 12th International Conference on Process Integration, Modelling and Optimisation for Energy Saving and Pollution ReductionPRES'O9 and the publishers of the Clean Technologies and Environmental Policy are joining their efforts and publishing this Special Issue.

PRES'O9 was held in Rome in 2009 and this annual conference is one of the world leading conferences of its kind. Being initially envisaged as a conference dedicated to process integration topics, it is nowadays a comprehensive and established platform for researchers, industry people and policy makers. It provided excellent opportunity for its participants to exchange novel ideas, processes, procedures

\section{J. J. Klemeš ( $\square)$}

Centre for Process Integration and Intensification-CPI2, Research Institute of Chemical Technology and Process Engineering, Faculty of Information Technology, University of Pannonia, Egyetem utca 10, 8200 Veszprém, Hungary e-mail: klemes@cpi.uni-pannon.hu

\section{Bulatov}

Centre for Process Integration, School of Chemical Engineering and Analytical Science, The University of Manchester, Oxford Road, Manchester M13 9PL, UK

e-mail: igor.bulatov@manchester.ac.uk and energy saving policies and establish close links between Academia and Industry and policy makers. What also distinguishes this conference from its counterparts is its strong and elaborate publishing strategy. All conference papers are now published as refereed papers in Chemical Engineering Transactions (Friedler 2009) which testifies for the quality of the contributions. Besides that, the selected conference contributions are published as considerably extended versions in special issues of various internationally recognised journals, including Clean Technologies and Environmental Policy.

Fifteen papers were invited for the publication and after a thorough peer-review following Clean Technologies and Environmental Policy reviewing procedure ten of them were selected. They have been authored by researchers from eight countries worldwide-from the Czech Republic, France, Hungary, Japan, Malaysia, Russian Federation, Slovenia, United Kingdom, and Taiwan.

This selection starts with an introductory conceptual/ philosophical article studying the interactions between the nature and the society. They are followed by another two thematic groups. The first group of papers is centred on environmental policy decision-making support systems and analysis. The second group is extending the environmental policies implementation into clean technologies process design and analysis.

Publication of Special Issues of Clean Technologies and Environmental Policy following yet another PRES conference have become a good tradition which is based on high quality of presentations delivered by the conference participants. We are convinced that providing broader access to the research and information contained in those presentations will be beneficial for wide range of the audience in industry, academy and local and central authorities. 
We are confident that the papers in this Special issue of Clean Technologies and Environmental Policy will be of interest and relevance to a broad range of the scientific community and hope it will also bring to their attention the PRES Conference series. This Special issue is building on the success and a positive response of those published previously (Klemeš and Bulatov 2008; Bulatov and Klemeš 2009, 2010).

After PRES'09 came the next, PRES 2010, conference. It was a joint conference with CHISA 2010 held in Prague from 28 August to 1 September 2010 as part of the 7th European Congress of Chemical Engineering ECCE-7. PRES 2010 received nearly 500 abstracts (PRES 2010) to choose from. In 2011 will be organised 14th PRES'11 conference in the heart of the renaissance art-in Florence (Firenze) in northern Italy. This will be another chance to progress with the cleaner technologies towards the sustainable and environmental policies.

The editors of this Special issue of the Clean Technologies and Environmental Policy offer our gratitude to more than 40 reviewers for their invaluable help and contributions. Many of you reviewed multiple papers and served as members of the PRES International Scientific Committee. Their dedicated effort made it possible to review/revise and to publish this Special issue in a comparatively short time after the conference. Their contribution has been most appreciated.

\section{References}

Bulatov I, Klemeš J (2009) Towards cleaner technologies: emissions reduction, energy and waste minimisation, industrial implementation. Editorial. Clean Technol Environ Policy 11(1):1-6

Bulatov I, Klemeš J (2010) Clean technologies: design aspects. Clean Technol Environ Policy 12(2):87-90

Friedler F (2009) Mathematical modelling in process design and operation: structural assessment. Chem Eng Trans 18:1-26

Klemeš J, Bulatov I (2008) Towards cleaner technologies minimising the environmental impact. Clean Technol Environ Policy 10(2):107-110

PRES (2010) PRES conference. www.conferencepres.com. Accessed 12 Aug 2010 